\title{
The 1994 Northridge earthquake: 3-D crustal structure in the rupture zone and its relation to the aftershock locations and mechanisms
}

\author{
Dapeng Zhao and Hiroo Kanamori \\ Seismological Laboratory, California Institute of Technology, Pasadena
}

\begin{abstract}
A detailed 3-D $P$-wave velocity structure of the crust in the epicentral area of the 17 January, 1994 Northridge earthquake is determined by using 104,709 arrival times from 1673 Northridge aftershocks and 2948 other local earthquakes. A test performed using the data from the nearby portable stations suggests that the aftershock hypocenters relocated with the obtained $3-\mathrm{D}$ model are accurate to about $2 \mathrm{~km}$. We found that regions with high aftershock activity are generally associated with faster $P$-wave velocities. The velocity is high around the main south-dipping fault of the 1994 Northridge earthquake and the north-dipping fault of the 1971 San Fernando earthquake. A linear distribution of strike-slip aftershocks was found along a NE-SW boundary between high-velocity and low-velocity structures. To the west of this boundary a cluster of large shallow aftershocks with mixed mechanisms occurred in or near the border of a low-velocity area, while to the east aftershocks with thrust mechanisms occurred in a high-velocity area. These observations suggest that lateral variations of crustal properties are closely related to the fault segmentation in the Transverse Ranges. A better understanding of these features is important for long-term seismic hazard assessment in the Los Angeles area.
\end{abstract}

\section{Introduction}

The 17 January, 1994 Northridge earthquake ( $M w$ 6.7) occurred in the San Fernando Valley northwest of Los Angeles, and caused widespread damage over a large area in the Los Angeles basin, though of moderate size. The Northridge earthquake occurred on a south-dipping fault beneath the Transverse Ranges, in striking contrast to the 1971 San Fernando earthquake that occurred on a north-dipping fault. Since the Transverse Ranges involve many active and complex structures formed under a regional N-S compressional stress system, a much larger earthquake could occur if the rupture extended over many segments of the fault system. In order to investigate whether there is any structural feature that may have influenced the rupture propagation of the Northridge earthquake, we determined a detailed 3-D crustal structure in the epicentral area and relocated the aftershocks accurately. We compared the

\section{Copyright 1995 by the American Geophysical Union.}

Paper number 94GL03222

0094-8534/95/94GL-03222\$03.00 obtained 3-D crustal structure with the aftershock distributions and mechanism variations, and found some intriguing correlations between these observations.

\section{Data and Method}

Figure 1a shows the 97 seismic stations of the CaltechUSGS Southern California Seismic Network (SCSN) which are used in this study. The 59 portable stations which were set up following the Northridge earthquake [Steidl et al., 1994] are also shown in the figure.

In order to have a complete set of uniformly distributed events for tomographic inversions, we used the following procedure to select events from more than 5000 Northridge aftershocks and about 50,000 local earthquakes. We divided the study area into blocks with a spatial size of $3 \times 3 \times 2 \mathrm{~km}^{3}$. Among the events within each block, we selected the event which has the greatest number of $P$-arrivals and the smallest error for

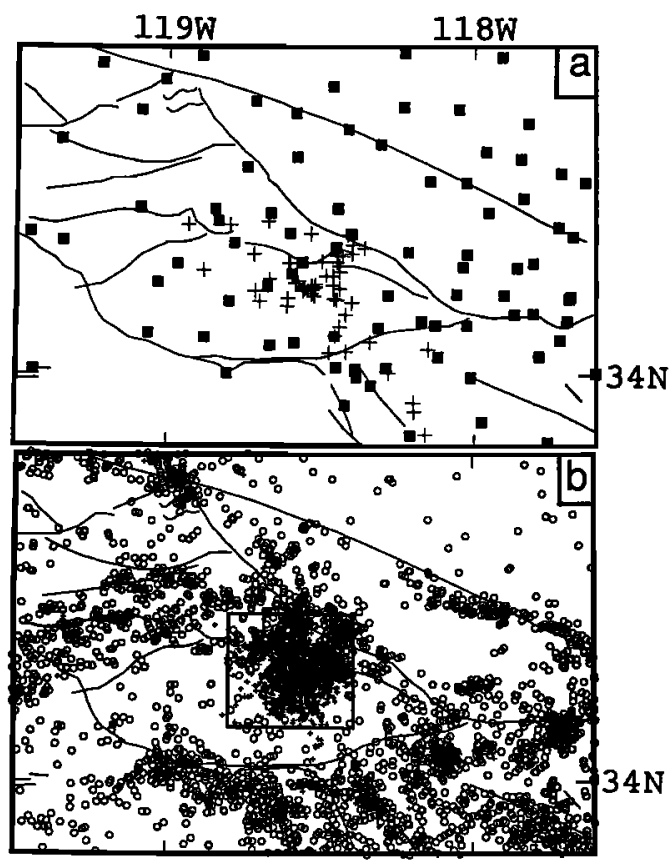

Figure 1. (a) Distribution of the 97 permanent seismic stations of the Caltech-USGS Southern California Seismic Network in the present study area (solid squares) and 59 portable stations (crosses) which were set up following the Northridge earthquake. (b) Epicentral locations of the events used in the tomographic inversion. Crosses denote 1673 aftershocks of the Northridge earthquake. Open circles denote 2948 selected local events which occurred from January 1984 to January 1994. The box shows the Northridge aftershock area. 


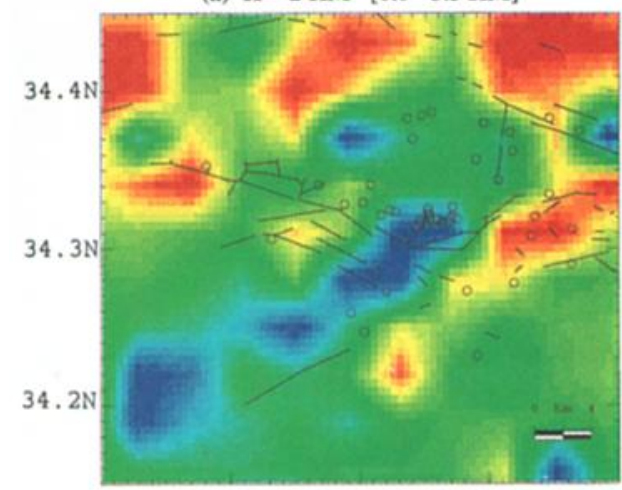

(d) $\mathrm{H}=11 \mathrm{KM}[9.5 \cdot 12.5 \mathrm{KM}]$

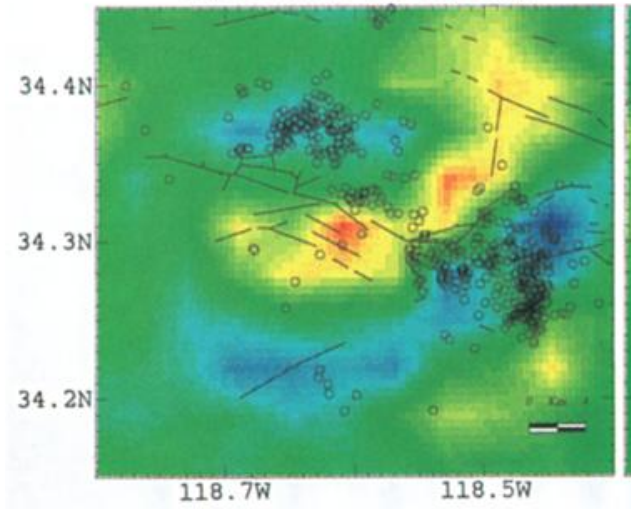

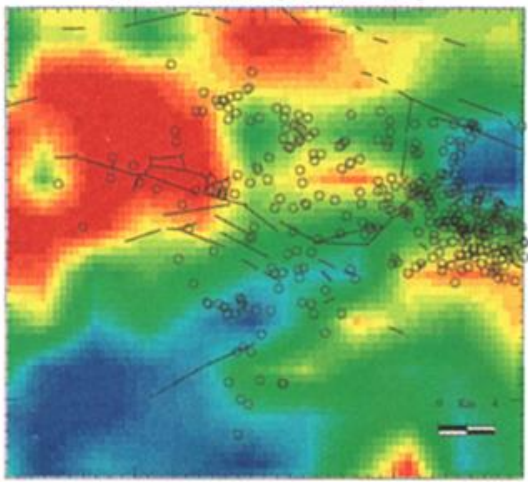

(e) $\mathrm{H}=14 \mathrm{KM}[12.5 \cdot 16.0 \mathrm{KM}]$

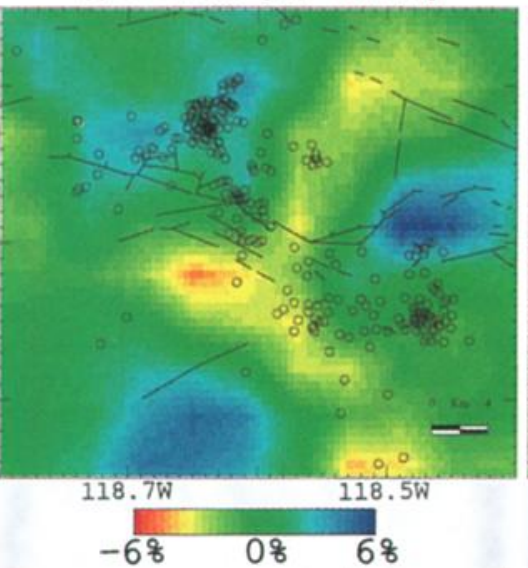

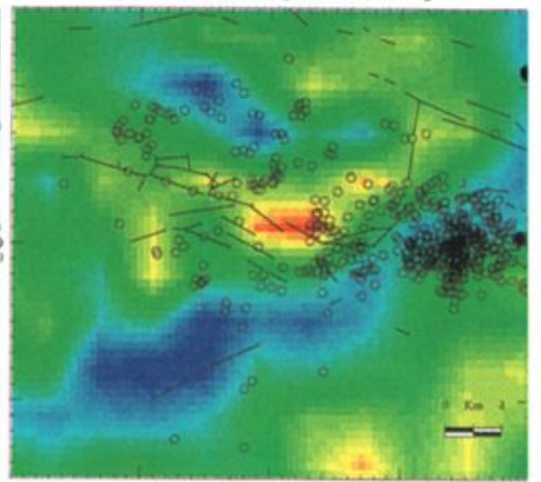

(f) $\mathrm{H}=18 \mathrm{KM}[16.0 \cdot 20.0 \mathrm{KM}]$

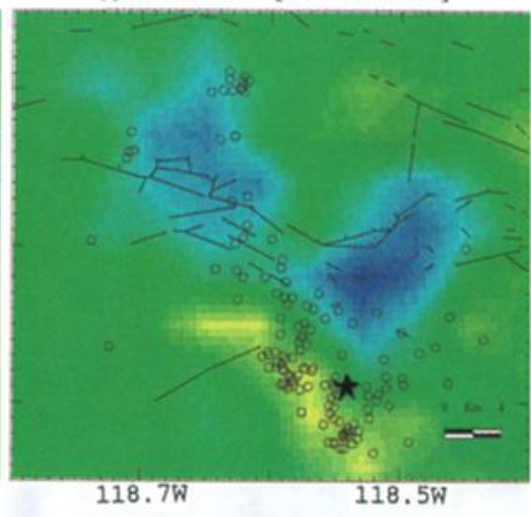

$118.5 \mathrm{~W}$

Figure 2. Fractional $P$-wave velocity perturbations (in percent) at six depth slices in the aftershock area (box in Figure 1b). Note that the perturbations are measured from the average of the velocities in the 3-D model. Red and blue denote slow and fast velocities, respectively. The velocity perturbation scale is shown at the bottom of the figure. Open circles denote the Northridge aftershocks which are relocated with the 3-D velocity model. The solid circle in the upper-right corner of Figure 2c shows the epicenter of the 1971 San Fernando earthquake. The star in Figure 2f shows the epicenter of the Northridge mainshock. Shown at the top of each map are the depth of each layer and the depth range of the aftershocks (in brackets).

the hypocentral location. As a result, we selected 1673 aftershocks which are recorded by more than 20 stations and have mislocation errors less than $3 \mathrm{~km}$. We also selected with the same procedure 2948 earthquakes which occurred around the Northridge epicentral area from January 1984 to January 1994. All these local events have more than $20 P$-arrivals. We believe that

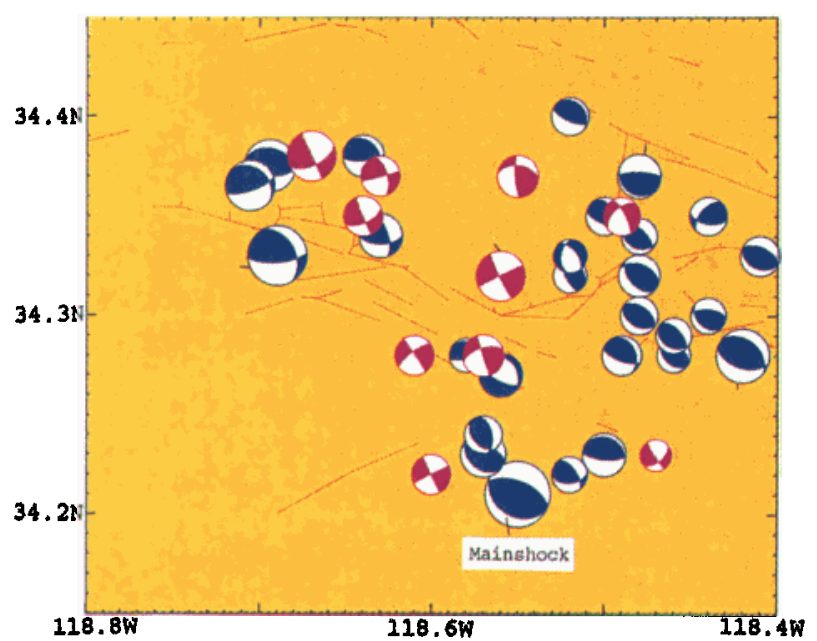

Figure 3. Locations and focal mechanisms of the mainshock and major aftershocks of the 1994 Northridge earthquake [modified from Thio and Kanamori, 1994]. we have selected the best data set from the available data base. Figure 1b shows the epicenters of the total 4621 events selected. The total number of $P$-arrivals from the 4621 events is 104,709 . The accuracy of the arrival times is better than $0.1 \mathrm{~s}$ for most of the data.

We used the tomographic method of Zhao et al. [1992] to analyze the arrival times. We set up grid nodes with a grid spacing of $3 \mathrm{~km}$ in the study area. Hypocentral parameters and $P$-velocities at the grid nodes are taken as unknown parameters. Travel times and ray paths are accurately calculated by using the 3-D ray tracing technique of Zhao et al. [1992]. The LSQR algorithm of Paige and Saunders [1982] is used to conduct inversions. Earthquakes are relocated in the inversion process.

\section{Results}

The Kanamori and Hadley [1975] crustal model is taken as the starting model for the inversion. We solved the inversion problem for $4621 \times 4$ hypocentral parameters and 16,097 velocity parameters at the grid nodes where more than 20 rays passed. The sum of squared travel-time residuals was reduced by $48 \%$ of its initial value after the inversion. Figure 2 shows $P$-wave tomographic images at six depth slices thus obtained. Each map includes epicenters of the Northridge aftershocks which are relocated with the obtained 3-D model. Fig- 

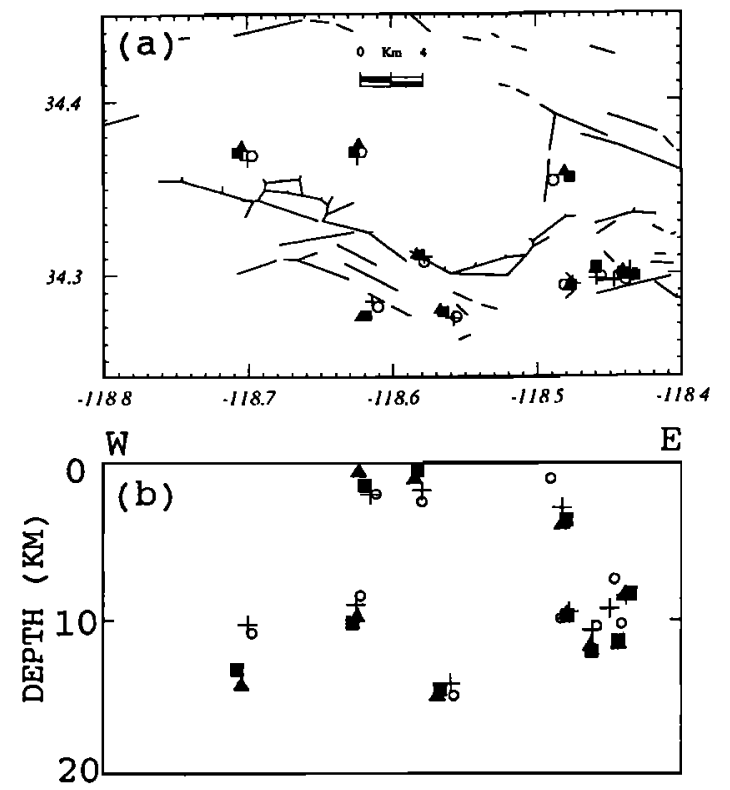

Figure 4. Comparison of hypocentral locations for 10 Northridge aftershocks determined with different models and data sets in a plan view (a) and an east-west vertical cross section (b). Open circles and crosses denote hypocenters with the SCSN data alone, and with the 1-D model and 3-D model, respectively. Solid triangles and solid squares denote hypocenters with both the SCSN data and the portable data, but with the 1-D model and 3-D model, respectively.

ure 3 shows locations and focal mechanisms of the Northridge mainshock and major aftershocks [Thio and Kanamori, 1994], which are discussed in detail in the next section.

We also conducted a number of inversions by changing the grid spacing, starting model and damping parameter, and by using different data sets. We found that the overall pattern shown in Figure 2 is very stable, though the amplitudes of the velocity anomalies in some areas are slightly different $(<2 \%)$ between the different inversion results. We also performed detailed resolution and error analyses for the obtained 3-D model using the checkerboard-type method [Zhao et al., 1992]. We found that the spatial resolution is high $(3-5 \mathrm{~km})$ in and around the aftershock area, but lower $(6-10 \mathrm{~km})$ for the fringe of the model. The standard errors for the obtained velocity perturbations are typically $1.5 \%$ for most part of the study area and $0.5-1 \%$ for the aftershock area, suggesting that velocity variations greater than $2 \%$ are significant.

In the above calculations, we used the data recorded only by the SCSN stations because the data from the portable stations were not available. After we completed the 3-D inversions, some of the waveform data from the portable stations became available. To examine the accuracy of the aftershock locations, we performed the following test. We selected 10 aftershocks shown in Figure 4 and read their first $P$ arrival times from the broadband seismograms recorded by the portable stations. The number of the portable data for each aftershock ranges from 3 to 29 . The reading accuracy is better than $0.05 \mathrm{~s}$. We first used the SCSN data alone to relocate the 10 aftershocks with the 1-D model of Kanamori and Hadley [1975] and our 3-D model (Figure
2). Then we combined the SCSN data and the portable data to relocate the aftershocks with both the 1-D and 3-D models. Figure 4 shows the hypocenters for the four cases. When both the SCSN data and the portable data are used, the hypocenters determined with the 1$\mathrm{D}$ model are very close to those with the 3-D model, suggesting that the hypocenters are well constrained by the combined data. The hypocenters determined with the 3-D model and the SCSN data alone do not deviate very much from those with the combined data. The difference between them is generally less than $2 \mathrm{~km}$, and less than $3 \mathrm{~km}$ for all the cases.

We calculated travel-time residuals at the portable stations using hypocenters determined with the 3-D model and the SCSN data alone, and drew a histogram of the number of events versus the residual for each of the portable stations. As a whole, the histograms show a normal distribution with an average travel-time residual ranging from -0.3 to $0.5 \mathrm{~s}$, and a standard deviation of less than $0.2 \mathrm{~s}$. The small standard deviation suggests that the hypocenter mislocation errors do not exceed $2 \mathrm{~km}$, which is consistent with the result shown in Figure 4. Most of the average residuals have their absolute values less than $0.3 \mathrm{~s}$. We believe that a substantial part of the average residual $(0.2-0.3 \mathrm{~s})$ is caused by the hypocentral mislocations $(1-2 \mathrm{~km})$. The remaining residual may represent the very shallow and local anomalies right beneath each of the portable stations.

The overall pattern of velocity distribution in the present study area (Figure 1) is consistent with that obtained in the large-scale study for southern California with a lateral resolution of about $25 \mathrm{~km}$ [Zhao and Kanamori, 1992; Zhao et al., 1994]. Although the structure in the aftershock area looks complex, the velocity is relatively high in the major fault zone of the Northridge earthquake (central-eastern area in Figures $2 c$ and 2d). In general, regions with high aftershock activity are associated with relatively high $P$-wave velocities, particularly at the depth range of $8-14 \mathrm{~km}$. In contrast, only a few aftershocks occurred in regions with low velocities. The mainshock of the 1971 San Fernando earthquake and its major rupture zone (see Figure 2c) are located in the same high-velocity (high-V) area as that of the Northridge earthquake.

We calculated $P$-velocities at the hypocenters of the 2014 well located aftershocks shown in Figure 2 using the obtained 3-D model. The result shows that 1309 $(65 \%)$ aftershocks occurred in high- $\mathrm{V}$ areas (i.e., $\Delta V / V$ $>0 \%)$, and $705(35 \%)$ occurred in low-velocity (low-V) areas $(\Delta V / V<0 \%)$. In the very low-V areas $(\Delta V / V$ $<-3 \%$ ), there are only $4 \%$ of the aftershocks.

\section{Discussion}

The aftershocks shown in Figure 3 can be divided into three groups: (1) Events with thrust mechanisms on the east side of the aftershock area. This group includes the mainshock; its focal depth is determined to be $18.2 \mathrm{~km}$ by SCSN and $19.7 \mathrm{~km}$ with our 3-D model. The events in this group are distributed on the main south-dipping fault plane. Events to the north are generally shallower than those to the south. (2) Strike-slip earthquakes in the middle of the aftershock zone, which are distributed 
on a NE-SW trend. (3) A cluster of mixed thrust and strike-slip events in the western edge of the aftershock area. This group includes the largest aftershock and consists of generally shallow events.

Events in Group 1 are located in the distinct high$\mathrm{V}$ area in Figures $2 \mathrm{~b}, 2 \mathrm{c}$ and $2 \mathrm{~d}$. Events in Group 2 are located along the NE-SW trending boundary between the high-V and low-V structures. This boundary is most distinct in Figures $2 \mathrm{c}$ and $2 \mathrm{~d}$. This correlation suggests that the main south-dipping fault is bounded to the west by a relatively low- $V$ structure and by a distribution of strike-slip earthquakes. The relatively abrupt termination of the aftershock area of Group 1 may be due to the sudden change in the strength of the crust to the west, as suggested by the change in velocity. The sudden strength change is probably related to the fault segmentation in the Transverse Ranges. The distribution of strike-slip earthquakes coincides with the boundary of the velocity change. Events in Group 3 are in or around the shallow low-V structure shown in Figure 2b. As shown in Figures $2 c$ and 2d, the low$\mathrm{V}$ structures are underlain by a high- $\mathrm{V}$ structure. The events in Group 3 appear to be distinct from those in Group 1 which are on the main thrust fault-plane. The Group 3 events are shallow and could have ruptured into the relatively soft sediments.

As described above, the seismic rupture zones of the 1994 Northridge and the 1971 San Fernando earthquakes are generally imaged with high velocities. Similar results have been reported for the Parkfield [Lees and Malin, 1990], Loma Prieta [Lees, 1990], Morgan Hill and Coalinga [Michael and Eberhart-Phillips, 1991], North Palm Springs [Nicholson and Lees, 1992], and Joshua Tree - Landers - Big Bear earthquake sequences [Zhao and Kanamori, 1993; Lees and Nicholson, 1993], though details are different for each earthquake. Although it is still unclear how seismic velocity is related to seismicity, high- $\mathrm{V}$ areas are generally considered to be associated with more brittle and competent parts of the crust which sustain seismogenic stress. In contrast, low$\mathrm{V}$ areas may represent regions of either higher degree of fracture, high fluid pressure, or higher temperatures where deformation is more likely to be aseismic. Compositional variations may be also responsible for velocity variations.

If this correlation generally holds, it has an important implication that seismic rupture zones are fixed in space throughout many earthquake sequences [Zhao and Kanamori, 1993]. To obtain more definitive pictures, however, higher resolution tomographic models are required, and more detailed investigations of rupture characteristics are necessary.

Acknowledgments. This work was funded by grants from the Southern California Earthquake Center (SCEC) and the National Science Foundation (EAR-9416120, EAR-
8920136). We used the data prepared by the SCEC Data Center. H. M. Iyer, J. M. Lees and an anonymous referee critically read the manuscript and provided helpful comments. Contribution No. 5450, Division of Geological and Planetary Sciences, California Institute of Technology, and SCEC Publication No. 123.

\section{References}

Kanamori, H., and D. Hadley, Crustal structure and temporal velocity change in southern California, Pure and Appl. Geophys., 113, 257-280, 1975.

Lees, J. M., Tomographic $P$-wave velocity images of the Loma Prieta earthquake asperity, Geophys. Res. Lett., $17,1433-1436,1990$.

Lees, J. M., and P. E. Malin, Tomographic images of $P$ wave velocity variations at Parkfield, California, J. Geophys. Res., 95, 21793-21804, 1990.

Lees, J. M., and C. E. Nicholson, Three-dimensional tomography of the 1992 southern California earthquake sequence: Constraints on dynamic earthquake rupture? Geology, 21, 387-390, 1993.

Michael, A. J., and D. Eberhart-Phillips, Relations among fault behavior, subsurface geology, and three-dimensional velocity models, Science, 253, 651-654, 1991.

Nicholson, C., and J. M. Lees, Travel-time tomography in the northern Coachella Velley using aftershocks of the $1986 M$ 5.9 North Palm Springs earthquake, Geophys. Res. Lett., 19, 1-4, 1992.

Paige, C. C., and M. A. Saunders, LSQR: An algorithm for sparse linear equations and sparse least squares, $A C M$ Trans. Math. Software, 8, 43-71, 1982.

Steidl, J. et al., SCEC portable deployment following the 1994 Northridge earthquake, Program for Northridge $A b$ stracts, The 89th Annual Meeting of the Seismological Society of America, Pasadena, April 5-7, 1994.

Thio, H. K., and H. Kanamori, Moment tensor solutions for the 1994 Northridge earthquake sequence, Program for Northridge Abstracts, The 89th Annual Meeting of the Seismological Society of America, Pasadena, April 5-7, 1994.

Zhao, D., and H. Kanamori, $P$-wave image of the crust and uppermost mantle in southern California, Geophys. Res. Lett., 19, 2329-2332, 1992.

Zhao, D., and H. Kanamori, The 1992 Landers earthquake sequence: Earthquake occurrence and structural heterogeneities, Geophys. Res. Lett., 20, 1083-1086, 1993.

Zhao, D., A. Hasegawa, and S. Horiuchi, Tomographic imaging of $P$ and $S$ wave velocity structure beneath northeastern Japan, J. Geophys. Res., 97, 19,909-19,928, 1992.

Zhao, D., H. Kanamori, and E. Humphreys, Simultaneous inversion of local and teleseismic data for the crust and mantle structure of southern California, Phys. Earth Planet. Inter., in press, 1994.

H. Kanamori and D. Zhao, Seismological Laboratory 252-21, California Institute of Technology, Pasadena, CA 91125. (E-mail: hiroo@seismo.gps.caltech.edu, dapeng@seismo.gps.caltech.edu)

(received September 19, 1994; accepted November 11, 1994.) 